International Conference on Research in Management \& Economics

Serbia | Belgrade | December 15-17, 2018

\title{
Memorable Tourism Experience and Tourist Satisfaction
}

\author{
Dr. Janardan Krishna YadavAssistant Professor \\ Jindal Global Business School, O.P. Jindal Global University, Sonipat, Haryana (India)
}

\begin{abstract}
Memorable tourism experience has been a recent focus of tourism academicians. There have been various studies that have focused on the antecedents, dimensions and behavioral intentions of the tourists in various settings. The present study focuses on the relationship of memorable tourism experience with tourist satisfaction, specifically the various dimensions of MTE scale (Kim, Ritchie, \& McCormick, 2012) were examined. Structure survey with Houseboat tourists in Kerala, India suggest different dimensions for the MTE scale. It was found that only four dimensions of MTEs namely hedonism, involvement, refreshment \& local culture were meaningfully contributing to the tourist's satisfaction. The results suggest the need for reexamination of MTE scale in various contexts before accepting the generalizability of the scale. Keywords: Memorable tourism experiences, Satisfaction, Houseboat tourism
\end{abstract}

